\title{
Sex Inversion in Hermaphrodite Teleosts
}

\section{ISSN: 2578-031X}

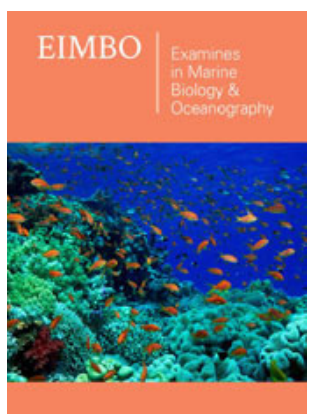

*Corresponding author: Moreira RG, Departamento de Fisiologia, Brazil

Submission: 㡓 February 05, 2019

Published: 眥June 04, 2019

Volume 3 - Issue 1

How to cite this article: Moreira $\mathrm{RG}^{*}$, Mello PH Araújo BC, Honji RM. Sex Inversion in Hermaphrodite Teleosts. Examines Mar Biol Oceanogr. 3(1). EIMB0.000551.2019.

DOI: 10.31031/EIMBO.2019.03.000551.

Copyright@ Moreira RG, This article is distributed under the terms of the Creative Commons Attribution 4.0 International License, which permits unrestricted use and redistribution provided that the original author and source are credited.

\author{
Moreira $\mathrm{RG}^{1 *}$, Mello $\mathrm{PH}^{2}$ Araújo $\mathrm{BC}^{3}$ and Honji RM${ }^{4}$ \\ ${ }^{1}$ Departamento de Fisiologia, Brazil \\ ${ }^{2}$ CAUNESP, Brazil \\ ${ }^{3}$ Mogi das Cruzes, Brazil \\ ${ }^{4}$ Centro de Biologia Marinha, Brazil
}

\section{Mini Review}

Sequential hermaphroditism is widespread among teleosts and contains one of the most striking expressions of plasticity in sexual development: sex change [1]. Protogyny is more frequent among teleosts and individuals are initially females; later, in adulthood, the ovaries are replaced by testes, transforming them into reproductively active males, whereas in protandry, the reverse occurs [1]. This process is known as sex inversion. Hermaphrodite species of simultaneous type, which present ovaries and testes simultaneously, are also known, but less frequently. Sex inversion is a very successful reproductive strategy among fish [2] and species that present this reproductive strategy have evolutionary advantages, translated by a plasticity that can be triggered by different environmental conditions, such as socio-demographic modulations in the case of serranids [3]. Many hermaphrodite teleost species are under critical conservation status and to produce them successfully in captivity, it is necessary to know the reproductive physiology of these species and the environmental modulations that are relevant in this process. Individuals in a population have a system that receives information from the external environment (environmental signals) and internal organs (physiological events), integrates them, regulates them, and results in a neuroendocrine control, which in turn triggers all physiological events that will lead to successful reproduction [4].

The majority of teleosts present the reproductive process modulated by environmental factors, such as temperature, photoperiod, rainfall, among other variables. However, the multiple and complex hormonal interactions between the sensory and reproductive organs, associated with the event of reproduction, are endogenously provided by an neuroendocrine system, involving primarily the hypothalamic-pituitary-gonadal (HHG) axis, which synthesizes and releases, gonadotropin releasing hormones (GnRHs), gonadotropins (GtHs), follicle stimulating hormone (FSH) and luteinizing hormone ( $\mathrm{LH})$, gonadal steroids (androgens, progestogens and estrogens). Neuromodulators also stimulate and / or inhibit this process (for example, dopamine, gonadotropin inhibiting hormone, gamma-aminobutyric acid, insulin-like growth factor, neuropeptide Y), among other substances [4]. Under suitable conditions for the animals, this whole process occurs naturally, with the development of the gonads, maturation, release and fertilization of the gametes, and in general, in teleosts, spawning and fertilization occur in the external environment. A permanent communication between the complex $\mathrm{H}-\mathrm{H}$ axis and the peripheral organs (particularly the gonads) allows the synchronization of all the steps of the life cycle. In this case, of importance in the communication between the $\mathrm{H}-\mathrm{H}$ axis and the gonads, are the sexual steroids, since they are indicators of the sexual status of vertebrates. These steroids can act in various tissues (such as the liver, pituitary, brain and gonad itself), altering the expression of neurohormones and/or neurotransmitters and/or other substances, as well as their respective receptors (feedback), as well as being important in sexual behavior at the time of spawning or sperm release by teleosts [4]. Once the H-H-G is known, phenotypic sex can be manipulated in teleosts by the administration of these sex steroids early in the animal's development, as for example in the sex inversion practices 
with methyl-testosterone (MT) in Epinephelus marginatus [5] and aromatase inhibitor in Epinephelus merra [6] and Epinephelus marginatus [7]. Thus, the maintenance of the female sex is related to estradiol levels and the decrease of this steroid can interrupt the vitellogenesis process and the oocyte maturation, as well as the promotion of the male sex in hermaphrodite animals.

The strong fishing pressure coupled with the lack of management planning of some serranid species, associated with the late sexual maturation of males, included some species in the IUCN (International Union for Conservation of Nature) list, as observed for Epinephelus marginatus [8]. To reverse this situation, the improvement of sex inversion techniques is important to obtain males, usually difficult to capture in the wild. This sex inversion technology makes possible the production of male gametes, thus performing the induced reproduction techniques, manipulating the H-H-G axis. The groupers are the most studied sequential hermaphrodites within teleosts, and sex inversion experiments have been carried out to induce sex inversion, allowing their production by aquaculture. The use of MT in juveniles of Epinephelus marginatus provides a permanent inversion, but without the production of semen, but the fertilization capacity of these spermatozoa was not tested in this protocol [5]. Using AI, the fertilization capacity of Epinephelus marginatus spermatozoa was demonstrated [7] as well as larvae production [9], but the authors did not test if sex change was permanent. Sex inversion in E. coiodes with MT can be divided into an early and an advanced phase, and that the characteristic of this inversion being permanent or not, depends on the moment at which the MT administration is interrupted [10]. Therefore, the efficiency of inversion in the production of male gametes, the fertilization capacity of gametes, as well as the permanent characteristic of sex inversion are processes that must be improved in protogynous hermaphrodite. The points raised here showed clearly that the physiological studies carried out with hermaphrodite teleosts, in different research areas, are important to gain some expertise to improve the rearing of these species that present a complex reproductive biology.

\section{References}

1. Devlin RH, Nagahama Y (2002) Sex determination and sex differentiation in fish: an overview of genetic, physiological, and environmental influences. Aquaculture 208(3-4): 191-364.

2. Mitcheson YS, Liu M (2008) Functional hermaphroditism in teleosts. Fish Fish 9(1): 1-43.

3. Shapiro D (1987) Differentiation and evolution of sex change in fishes. Biol Sci 37: 490-497.

4. Zohar Y, Muñoz CJA, Elizur A, Kah O (2010) Neuroendocrinology of reproduction in teleost fish. Gen Comp Endocrinol 165(3): 438-455.

5. Sarter K, Papadaki M, Zanuy S, Mylonas C (2006) Permanent sex inversion in 1-year-old juveniles of the protogynous dusky grouper (Epinephelus marginatus) using controlled-release $17 \alpha$-methyltestosterone implants. Aquaculture 256(1-4): 443-456.

6. Bhandari RK, Komuro H, Mikihiko H, Massaru N (2009) Sex inversion of sexually immature honeycomb grouper (Epinephelus merra) by aromatase inhibitor. Zool Sci 21(3): 305-310.

7. Garcia CEO, Mello PH, Araújo BC, Narcizo AM, Rodrigues FJA, et al. (2013) Involvement of pituitary gonadotropins, gonadal steroids and breeding season in sex-change of protogynous dusky grouper, Epinephelus marginatus (Teleostei: Serranidae), induced by a nonsteroidal aromatase inhibitor. Gen Comp Endocrinol 192: 170-180.

8. Rodrigues FJA, Sanches EG, Garcia CEO, Sebastiani EF, Pannuti CV, et al. (2009) Threatened fishes of the world: Epinephelus marginatus (Lowe 1834) (Serranidae: Epinephelinae). Environ Biol Fish 85(4): 301-302.

9. Mello PH, Araújo BC, Campos MF, Rodrigues FJA, Garcia CEO, et al. (2018) Embryonic and larval development and fatty-acid profile of Epinephelus marginatus spawned in captivity: Tools applied to captive rearing. J Fish Biol 92(4): 1126-1148.

10.Wang Q Liu Y, Peng C, Wang X, Xiao L, et al. (2017) Molecular regulation of sex change induced by methyltestosterone -feeding and methyltestosterone -feeding withdrawal in the protogynous orangespotted grouper. Biol Reproduc 97(2): 324-333. 